\title{
(How) Is Aging a Health Policy Problem?
}

\author{
Joseph White, Ph.D.*
}

\section{INTRODUCTION}

During the 1990s, the claim that an aging population constituted a long-term "crisis" became a policy cliché. This assertion became particularly popular among elite journalists and academics in the United States. For example, Washington Post columnist David Broder wrote of "the fiscal calamity that the retirement of the baby-boom generation poses for the early years of the next century." Former Director of the Congressional Budget Office (and current President of the Urban Institute) Robert Reischauer referred to "the demographic tsunami of the baby boom's retirement." Moreover, the Congressional Budget Office and U.S. General Accounting Office began issuing reports projecting the date of economic doomsday caused by spiraling deficits that would be caused, in turn, by burgeoning pension and health care costs. ${ }^{3}$ Because Medicare costs have grown far more quickly than Social Security obligations-though the latter will still remain larger than the former for many years-and because a significant portion of Medicaid spending also covers the elderly, much of this commentary has focused on health care costs in particular. Eminent health economist Victor Fuchs wrote that health care costs for the elderly "could plunge the nation into a severe economic and social crisis within two decades." Former Colorado Governor Richard D. Lamm wrote of "the

* Luxenberg Family Professor of Public Policy at Case Western Reserve University, Cleveland, Ohio. An earlier version of this Article was written for an international health policy conference that chose the challenge posed by aging as it theme. I therefore thank the organizers of the Four Country Conference: Aging and Health Policy, held in Gananoque, Ontario, Canada on July 12-14, 2001, especially the staff of the International Affairs Directorate of Health Canada, for their encouragement.

1. David S. Broder, The Party's Over: By 2000, the GOP or the Democrats Could Fade in Favor of a Third Party, WASH. POST, Aug. 11, 1999, at Cl.

2. Burt Solomon, OK, Now What?, 28 NAT'LJ. 2394, 2394 (1996).

3. JOSEPH WhITE, FALSE Al.ARM 73-98 (2d ed. 2003).

4. Victor R. Fuchs, Health Care for the Elderly: How Much? Who Will Pay?, HEALTH AFF., 
moral imperative of limiting elderly health entitlements," claiming that program costs would otherwise impoverish the young. ${ }^{5}$

Jeremiads about the challenges of aging in general, and of paying for the health care costs of the elderly in particular, have been especially loud in the United States, where they have dovetailed conveniently with an underlying ideological campaign to cut government programs. ${ }^{6}$ However, these demographic trends and budgetary pressures exist in all countries, and so this concern is heard around the world. Indeed, it has become a common theme in the international policy community. ${ }^{7}$ The World Bank, for example, has promoted this view of imminent crisis through its study Averting the Old Age Crisis and subsequent publications and conferences. ${ }^{8}$ These worries regarding cost and inequity are based on plausible inferences. As people age, they tend to have higher medical expenses. Thus, if a larger portion of the population consists of older people, one might expect higher medical spending. In turn, pressure for higher spending poses issues of policy-how to pay, whether to pay-and ethicsthe moral basis for providing or withholding benefits.

Yet, I will argue that, as a matter of both policy and ethics, policymakers and citizens need not worry about the implications of aging for medical costs. Aging of the population has some effect on health costs, but a much smaller effect than those factors that are both more susceptible to manipulation and pose less difficult ethical dilemmas. The aging of the population does pose economic and budgetary challenges, but the contribution of health care costs to this equation is relatively minor; policymakers would do better to focus on other concerns such as pension expenses and participation in the workforce. For these reasons, the health care costs of an aging population do not justify changes in health policy that would not otherwise be appropriate.

Nonetheless, aging poses a distinct health policy problem, which is only beginning to receive attention: The challenge will be less how to finance care than how to deliver it. The delivery challenge has two dimensions-how the health care system is organized and whether the

Jan.-Feb. 1999, at 11, 11.

5. Richard D. Lamm, The Moral Imperative of Limiting Elderly Health Entitlements, in POlicies fOR AN Aging SocieTy 199, 199 (Stuart H. Altman \& David I. Shactman eds., 2002).

6. See generally WHITE, supra note 3.

7. See, e.g., ORG. For ECON. CoOperation \& Dev., AgING IN OECD Countries (Soc. Pol'y Stud. No. 20, 1996) [hereinafter AgING In OECD CounTries]; Peter Hicks, The Impact of Aging on Public Policy, OECD OBSERVOR, Dec.-Jan. 1996, at 19.

8. WORLd BANK, AVERTING THE Old AGE CRISIS (1994). 
necessary workers or caregivers will be available.

This Article begins by putting in perspective the effect of aging on health care spending. I compare aging to other factors and explain why America's peculiar health care finance system exaggerates our perception of the aging crisis. I challenge the notion that a growing population of the "old old," i.e., individuals age eighty-five and over, will be so expensive as to create severe ethical dilemmas. Next I look more closely at the distribution of costs and benefits between the elderly and other citizens. Specifically, I argue that increased longevity does not change the fairness of pay-as-yougo social insurance. Higher costs will call for tradeoffs, but there are good reasons to argue that health care for the elderly in particular should not be reduced. Rather, policymakers would do better to use caution today in all dimensions of budgetary policy to make choices easier in the future. They should also take steps to increase workforce participation, especially among the elderly.

Finally, I turn to what I see as the more significant effects of an aging population - the effects on demand for services, and the almost inevitable mismatch between the organization and supply of services on the one hand and geriatric care needs on the other. In this regard, long term care-which does not fit squarely into the categories of medical care, social service, or income protection-is of particular interest.

This Article is based on a review of the situation in the nations of the Organization for Economic Cooperation and Development (OECD) more generally. A comparative perspective reveals that discussion outside the United States is beginning to move beyond a simplistic focus on the "crisis" of future health care costs associated with an aging society. It is time for discussion within the United States to do the same.

\section{Putting the Health Care Spending Effect of Aging in Perspective}

\section{A. Aging Compared to Other Factors}

All other things being equal, an aging society should increase the share of gross domestic product (GDP) that is dedicated to medical services. The denominator reflects the number of workers, while the numerator depends on demand for medical services. The aging problem, as conventionally conceived, arises from the supposition that a larger share of the population will retire each year. Hence, the elderly population will rise more quickly than the supply of workers. As a result, if the population that demands medical services grows more quickly than the working population, spending on medical services can be expected to grow more 
quickly than national production.

Yet all other things are never equal, and health care costs as a share of GDP depend on far more than demographic factors. Namely, health care costs depend on the extent to which new services are made available to citizens of all ages, on the extent to which those new services replace or supplement previous methods of care, and above all, on the prices paid for whichever services are provided. According to OECD statistics, the United States has the second smallest proportion of the population over age sixtyfive among all rich democracies, yet by far the highest health care spending as a percent of GDP. ${ }^{9}$ Why? As Gerard Anderson and colleagues argue, "It's the Prices, Stupid!"10 We simply pay much more per service.

In some analyses, such non-demographic factors overwhelm any effect of population aging on spending. As Marmor and Oberlander have summarized, "[F]rom 1960 to 1990 there was no correlation across OECD nations between aging populations and growth in medical costs."11 Using different techniques, Gruber and Wise reported that, from 1980 to 1991, there was a positive but not statistically significant relationship between the elderly share of the population and national health spending. ${ }^{12}$ That relationship might imply, for example, that aging would cause health care spending in average OECD nations to rise by about $0.9 \%$ of GDP between 1990 and $2025 .^{19}$ However, that is distinctly smaller than the estimated

9. Population 65 Years Old and Over - \% of Total Population, Org. for Econ. Cooperation \& Dev., at http://www.oecd.org/dataoecd/13/29/1935784.xls (last visited Jan. 7, 2004) [hereinafter Population 65 Years Old and Over]; Total Expenditure on Health - \% GDP, Org. for Econ. Cooperation \& Dev., at http://www.oecd.org/dataoecd/13/17/1935602.xls (last visited Jan. 7, 2004) [hereinafter Total Expenditures on Health]. In the year 2000, 12.3\% of Americans were 65 or over-tied with Australia and ahead of New Zealand at 11.7\%.

Population 65 Years Old and Over, supra. The United States spent 13\% of GDP on health care; the nearest competitor was Switzerland at $10.7 \%$. Total Expenditure on Health, supra.

10. Gerard F. Anderson et al., It's the Prices, Stupid: Why the United States Is So Different from Other Countries, HEALTH AfF., May-June 2003, at 89, 90.

11. Theodore R. Marmor \& Jon Oberlander, Rethinking Medicare Reform, HEALTH AFF., Jan.-Feb. 1998, at 52, 55.

12. Jonathon Gruber \& David Wise, An International Perspective on Policies for an Aging Society, in POLICIES FOR AN AGING SOCIETY, supra note 5, at $34,57$.

13. Gruber and Wise report a coefficient of 0.099 , meaning that health spending as a percent of GDP would rise by 0.099 points for each one point increase in the elderly share of the total population. Gruber \& Wise, supra note 12, at 55. The average percentage of population age sixty-five in OECD nations is projected to rise from $12.2 \%$ in 1990 to $21 \%$ in

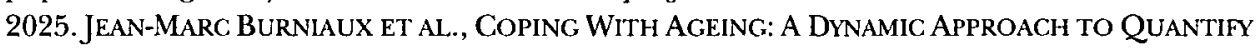
THE IMPACT OF Alternative POLICY Options ON Future LABOUR SUPPLY IN OECD COUNTRIES 
impact of other cost-increasing dynamics-which tend to be summarized as "technological progress." A recent German study, for example, concluded that, due to aging, contribution rates to the sickness funds in Germany would have to rise from $13.6 \%$ of covered payroll to $16 \%$ by $2040 .^{14}$ "By comparison," it added, "technological progress will more forcefully add the upward pressure producing a contribution rate of $23 \%$."

\section{B. Medicare's Deceptive Problem}

An aging United States population will raise Medicare costs proportionately more than those of any other nation's national health care/insurance system. In all other rich democracies, when a person turns sixty-five the incremental cost to the national insurance fund, health service, or mandated insurance scheme is only the difference between that person's medical costs at ages sixty-four and sixty-five. Because Medicare only covers the elderly and the disabled, when a person turns sixty-five the entire cost to Medicare is new.

However, it is a new cost only to the federal budget. When a person is added to the Medicare budget, costs to other payers, such as employers, fall; even the federal government may have an offsetting gain if it was previously granting a tax subsidy to an employer for providing private insurance. ${ }^{16}$ If we were to consider society as a whole, or if the United States-like other wealthy democracies-guaranteed health care or insurance to anyone other than the elderly, the demographic effect would look smaller.

The aging population might be expected to raise Medicare spending

71 (OECD Econ. Dep't Working Paper No. 25, 2003). That increase in the aged population share, multiplied by the Gruber and Wise coefficient, yields slightly less than a $0.9 \%$ of GDP increase in health spending. Note, however, that Gruber and Wise's estimate had a standard error of 0.069 , so should be treated with caution. Gruber \& Wise, supra note 12.

14. JuRgen von Hagen \& Rolf R. STRAuCh, German PUblic FinanCes: RECEnT Experiences AND FutURe Challenges 4 (Ctr. for Eur. Integration Stud. Working Paper No. B13, 2001).

15. Id.

16. The example of a person who is employed to age sixty-five, has health insurance through employment, and then retires and goes on Medicare is, of course, a simplification. Many people retire earlier, have some mix of coverage then from their former employer or other sources (e.g., a spouse's employer), or never had insurance. However, in virtually all cases people who go on Medicare are giving up some other coverage, and the sponsor of the other coverage therefore is saving money. 
by slightly more than two percent of GDP between 2000 and $2070 .{ }^{17}$ But the Medicare Trustees projected that spending would rise by a total of $6.2 \%$ of GDP over the same seventy years. ${ }^{18}$ In short, spending increases due to non-demographic factors are expected to be nearly double the level of increases resulting from demographic changes. These assumptions do indeed make Medicare seem unaffordable. Moreover, when applied to the health care system as a whole, these same assumptions yield presumably untenable results. If they are correct, American health care spending will rise to thirty-eight percent of GDP by $2075 .{ }^{19}$ Clearly that would be a far more severe circumstance than the roughly two percent of GDP increase in Medicare costs attributed to demographic trends.

Thus, there is plenty of reason to worry about health care cost control. ${ }^{20}$ Unfortunately, there is no credible evidence that changes in Medicare's entitlement, sometimes promoted as solutions to the cost problem, would do any good at all. The usual reform suggestion is that Medicare be turned from a defined benefit program, in which the federal government provides insurance for a standard set of benefits, into a "premium support" system, in which the federal government provides a contribution and individuals purchase insurance from a set of public and private options. However, the available data do not lend support to the idea that competition and privatization would save money. ${ }^{21}$ For example,

17. I do not have access to estimates of this precise effect. But, for example, the Congressional Budget Office estimated in 1998 that demographic factors alone would raise Medicare spending from $2.6 \%$ of GDP in 1995 to $4.4 \%$ in $2030,4.5 \%$ in 2050 and $4.8 \%$ in 2070. Cong. Budget Office, LonG-Term Budgetary Pressures and Policy Options 49, 58 tbls. $4.2 \& 4.5$ (1998). It is important to note that spending net of enrollees' premiums would be a bit lower and the baseline for these 1998 estimates was significantly higher than actual spending in 2000 . That is why I adjusted the figures as I did.

18. Bd. Of Trs. Of The Soc. SeC. \& Medicare Trust Funds, 2003 ANnual Report On the STATUS OF FEDERAL HOSPITAL INSURANCE TRUST AND SUPPLEMENTARY INSURANCE TRUST FUNDS 29 (2003), available at

http://www.cms.hhs.gov/publications/trusteesreport/2003/tabiia3.asp.

19. Health Care Fin. Admin. , Technical Review Panel on the Medicare Trs. Reports, Review of Assumptions and Methods of the Medicare Trustees' Financial Projections 30 (2000), available at http://www.cms.gov/publications/technicalpanelreport/report.pdf.

20. I have argued elsewhere that policymakers could never adopt policies to promise some controlled level of spending more than a few years in the future. See, e.g., WHITE, supra note 3, at 110-13. Yet they should still control costs in the short run by any responsible methods they can find, following the best available information.

21. See WHITE, supra note 3, at 252; Marsha Gold, Can Managed Care and Competition Control Medicare Costs?, HEALTH AFF., Apr. 2, 2003 Web Supplement, at W3-176, available at http://content.healthaffairs.org/cgi/reprint/hlthaff.w3.176vl.pdf. 
even after two successive years (1997 and 1998) in which traditional Medicare spending per enrollee slightly shrank, Medicare's costs per enrollee grew by only about twenty-five percent from 1999 through 2003, while private insurance premiums rose by about fifty-five percent. ${ }^{22}$ Given Medicare's superior cost control performance, arguments that it must be reformed to look more like private insurance due to the coming demographic crisis are questionable at best. It would be more reasonable to infer that the rest of the system should be reformed to more closely resemble Medicare.

\section{The Mythical Ethical Challenge of the "Old Old"}

Within the general fear-mongering about health care costs for the elderly, one issue is treated as raising particularly severe ethical and financial issues: the growth in the population of "old old." The theory is that very old and frail people incur particularly high medical costs and that those costs are unproductive from a societal perspective since those people will die soon anyway. ${ }^{23}$ Such financial concerns may be joined with bioethical concerns about the appropriateness of extending life for people with few prospects of surviving or worries about the need to allocate care in such a way that expensive care for the very old does not divert resources from care for younger persons.

Fortunately, as it turns out, neither end-of-life care nor aging within the elderly population makes much of an independent contribution to increases in total health care system costs. For example, within Medicare, spending at the end-of-life has remained a nearly constant share of total costs. $^{24}$ Population aging turns out to have cost-saving as well as costincreasing implications.

Costs for an eighty-year-old person are, on average, much higher than

22. I arrived at this figure by using data from BD. OF TRS. OF THE SOC. SEC. \& MEDICARE TRUST FundS, 2003 ANNUAL REPORT ON THE STATUS OF FEDERAL HOSPITAL INSURANCE TRUST AND SUPPLEMENTARY INSURANCE TRUST FundS 29 tbl.IV.B1 (2003), available at http://www.cms.hhs.gov/publications/trusteesreport/2003/tabivb1.asp. See also Bradley C. Strunk et al., Tracking Health Care Costs: Growth Accelerates Again in 2001, HEALTH AFF., Sept. 25, 2002 Web Supplement, at 299, 306; Bradley C. Strunk et al., Tracking Health Care Costs: Trends Stabilize but Remain High in 2002, HeALTH AFF., Jan.-June Web Supplement, at 266, 272, available at http://www.openminds.com/indres/Health\%20Affairs\%20June\%202003.pdf.

23. See Peter G. Peterson, Will America Grow Up Before it Grows Old? $26-27$ (1996).

24. James Lubitz et al., Longevity and Medicare Expenditures, 332 NEw ENG. J. MED. 999 (1995). 
for a sixty-five-year-old person. ${ }^{25}$ The major reason is that an eighty-year-old is more likely to die, and mortal illness tends to be expensive. As life expectancies increase, there will be more eighty-year-old people, but each of them will also be less likely to die. Thus, the average cost of eighty-yearolds should go down as the number of eighty-year-olds goes up. Analyses have shown the two effects largely canceling each other out, not only in the United States's Medicare program, but in Switzerland ${ }^{26}$ and across the OECD nations. ${ }^{27}$

Could the future have a different dynamic than the past? I have noted that longevity increases have been associated with lower spending at a given age because fewer people are dying at that age and dying is expensive. However, it is possible that future increases in life expectancy will be attributable to highly expensive medical interventions. In other words, there could be just as many eighty-year-olds having what would now turn out to be fatal illnesses in 2030 as there are today; their treatment could be as or more expensive in constant dollars; and more of the treatments could work. Then increased longevity would cause extra costs with no offsetting savings. That is possible, but entirely speculative. With equal logic, one could project that certain medical innovations (e.g., in cardiac care) will be relatively efficient; people will be "saved" more cheaply, and then die quietly of old age, also cheaply. Medicare data show that "the costs of medical treatment near death decrease with increasing age of death." ${ }^{28}$ For the moment, it is reasonable to hypothesize that longevity increases in the future will have roughly the same profile as in the past.

If we extrapolate from experience to date, the organization and finance of health care will have far more effect on both the cost and quality of future medical care than will the effects of demographic change. From this perspective, population aging is, as Peter Zweifel and colleagues have suggested, a "red herring."

25. House Comm. ON WAYS \& MEANS, 104TH CONG., 1996 GREen BoOK: BACKGROUND

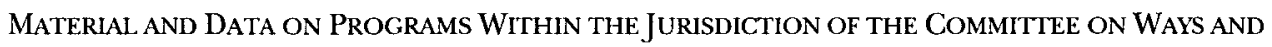
Means 246-47 tbls.3-50 (Comm. Print 1996).

26. Peter Zweifal et al., Aging of Population and Health Care Expenditure: A Red Herring?, 8 HEALTH ECON. 485 (1999).

27. See Howard Oxley \& Maitland MacFarlan, Health Care Reform: Controlling SpENDING ANd InCREASIng EFfiCiency (OECD Econ. Dep't Working Paper No. 149, 1994); see also AGING IN OECD COUNTRIES, supra note 7.

28. Lubitz et al., supra note 24 , at 1001.

29. Zweifal et al., supra note 26. 


\section{Distribution BetWeEn THE Elderly and OTHER Citizens}

We have seen that demographic trends have a relatively small effect on health care costs, and in particular, the fear of increasing costs for the "old old" is not justified. Yet an important normative question remains: If there are more elderly compared to the number of workers, does that mean that publicly guaranteed benefits for the elderly should be reduced? In the standard formulation, "our children" will pay more for our health care when we retire than we did for "our parents" health care, because we are expected to live longer than our parents. Is that fair?

\section{A. Why Increasing Longevity Does Not Make Pay-as-You-Go Systems Unfair}

As the point is commonly argued in the case of pensions, the burden on "our children" or "our grandchildren" should be reduced by shifting from a system in which each generation pays for its predecessors through taxes to one in which the currently aging group pays for itself through some system of savings. In pension terms, it would be a shift from "pay-asyou-go" to "pre-funding." Such an approach has been recommended for health care by one of the two current public trustees of the Medicare program, Thomas Saving. ${ }^{30}$

However, there is apparent inequity in changing from a pay-as-you-go system to a pre-funded arrangement: Some generation must pay twice, financing its elders in addition to pre-funding itself. Moreover, that inequity is unnecessary, since increasing life expectancies do not themselves alter the relative merits of pay-as-you-go funding.

In a pay-as-you-go system, the average person born in 2000 will pay more for retirement pension and health expenses than will the average person born in 1980 because the number of individuals who are retired during the life of a person who is born later will, other things equal, be increased due to the fact that more people will live to retirement and, once retired, they will live longer. That's what increased life expectancy means. Yet the same logic applies to the individuals themselves: Increased life expectancy for a person born in 2000, compared to a person born in 1980 , means the former would have to save more for herself alone because the ratio between her own years in retirement and years in work would be larger. Thus, either way, increasing longevity has the same effect. People born later have to set aside a larger share of their income while working,

30. Phil Gramm et al., Medicare Policy for Future Generations: Search for a Permanent Solution, 338 NEW ENG.J. MED. 1307 (1998). 
either through taxes to support those who have previously retired or savings to support themselves. The only legitimate question is how people can best guarantee themselves some security in old age, and greater longevity does not alter the relative security of tax-based redistribution as compared to individual savings. ${ }^{31}$

In practice, people contribute to social insurance systems, such as Social Security and Medicare, as part of a compulsory social contract, in which paying taxes to support others creates one's claim to benefits for one's self later. This contract has risks, but so do market investments. Each is a way to make claims upon the future; if there is an ethical difference it is in how they distribute risks.

The basic argument for social insurance approaches is that they spread risk in a more socially acceptable way than if the elderly relied entirely on family and market claims to benefits. Social insurance redistributes from high-earners to low-earners, from the relatively well to the sick, and from those with shorter lives to those who live longer. Compared to relying on personal investments, access to adequate living standards (including healthcare) while retired in a social insurance system depends much less on one's income while working, degree of luck with investments, and longevity after retirement. Reliance on intra-family transfers carries the same risks as personal investments, especially since individuals with low incomes tend to have children with low incomes, and so a parent's misfortune would be doubly visited upon his or her children.

\section{B. Pressure on Other Programs or Incomes}

One might argue, however, that even a small increase in costs due to aging is "unaffordable" because the money could be better spent on other programs or better left in private pockets. In this view, health care costs for the elderly would be taken from education or aid to impoverished children, other public "investments in the future," national security, or private investments to develop the economy.

This argument has two components-one economic and one distributional. The common doomsday scenario claims that higher health

31. The argument here does not apply to situations of unequal cohort size. There is more of an argument for having the baby boomers in some sense "pre-fund" their costs in retirement than for pre-funding simply due to increasing longevity. The boomers, however, can pre-fund their costs in more temporary and flexible ways, such as by creating budgetary conditions that decrease government debt obligations. Reducing debt service costs from 2020-2035, for instance, would free up revenues that could be used to cover some of the extra pension and health costs due to the size of the baby boom cohort. 
care costs will devastate the economy. This argument assumes that government will incur these costs, but not raise taxes or reduce other spending to pay for them. Following that scenario, government deficits would rise steadily as borrowing yields higher interest costs and thus more borrowing. Eventually deficits would be so high that they would consume all possible sources of investment and so could be financed only by running down the nation's capital stock, destroying the economy. ${ }^{32}$ Although this vision has been widely promoted, there is no reason to assume governments will let the budget situation become so dire. Governments respond to rising deficits by taking steps to control them, even if they do not do so as quickly or thoroughly as "deficit hawks" wish. Scenarios that presume governments will let deficits spiral irredeemably out of control are extremely speculative. Moreover, raising taxes to pay for this government spending may have little effect on the economy. ${ }^{33}$

The more serious issue is how the choices governments are likely to make to control deficits will affect citizens. From this perspective, what might be called the "affordability" of health care for the elderly is really a matter of preferences. The money could arguably be taken from other government programs that do not work as well, or, by taxes, from private consumption that one could consider to be of less social value. Whether health care for the elderly is less important than military spending, or than wealthier individuals buying more expensive automobiles, or than citizens' ability to consume liquor and tobacco, or than governments propping up declining industries, or than any other alternative consumption, are political and moral judgments that will be made differently by different people.

Only two things should be clear about such choices. First, health care spending for the elderly is not obviously less important than a whole range of alternative expenditures. Second, judgments about distributional tradeoffs concerning future consumption are best made by future consumers, according to their preferences, rather than by us. We certainly

32. This doomsday scenario is at the heart of a series of forecasts done by the U.S. General Accounting Office beginning in 1992 and the U.S. Congressional Budget Office

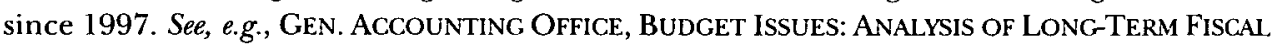
OUTLOOK (1997).

33. The evidence that raising taxes somewhat to pay for government spending as a share of GDP must have significant negative economic effects is quite weak. Available data are less than great, but for one simulation of effects, see KETIL. HVIDING \& MARCEL MérETTE, Macroeconomic Effects of Pension Reforms in the ConteXt of Aging Populations (OECD Study on the Pol'y Implications of Aging Working Paper No. 3, 1998). For a more extensive discussion and citation to U.S. analyses, see WHITE, supra note 3, at 73-98. 
have no reason to assume that voters in, for example, 2020 will prefer to cut health care for the elderly-especially since voters in no rich democracy to date have made a similar choice.

Under what circumstances would reductions in health care targeted to the elderly be justified? It is surely reasonable to believe that health care, in principle, should be one of the highest priorities for social sharing. Pain, disability, and death are things most people would pay to avoid before they would purchase whatever else might be bought with, for example, the last twenty percent of an average retiree's income. Inequalities in access to relief of pain, or in access to life-saving treatment, may seem less acceptable than other inequalities.

Some commentators believe that social sharing to provide health care to eighty-year-olds is inherently less desirable than providing care to younger citizens. In Richard Lamm's words, "[w]e have created a Faustian bargain, according to which our aging bodies can and will divert resources that our children and grandchildren need for their own families and that public policy needs for other important social goods." ${ }^{34}$ Yet Lamm's belief that a decent society would guarantee less health care to an eighty-year-old than to a forty-year-old does not appear, judging from existing social policies around the world, to be a common belief. In all rich democracies, access to medical care is more equalized than access to other goods, and there is no explicit discrimination against the old. ${ }^{35}$ In the United States, the elderly are actually favored, being the only group guaranteed health insurance-perhaps because they are the group with the most obvious need. One reason for these policies may be that the distinction between the elderly and other people is ephemeral: Most individuals hope to be elderly some day. Another is human sympathy: Most people are likely to have elderly loved ones whose lives they value. And some objections may be moral: Defining some lives as more valuable than others simply due to age is incompatible with many ethical and religious traditions.

Policymakers can make future trade-offs easier by adopting more cautious policies in the present. They should be careful to control health care costs as much as possible. They should also avoid unnecessary military spending, cut taxes only if they can be sure not to create deficits that will cause higher interest costs, and avoid starting new programs of any sort

34. Lamm, supra note 5, at 203.

35. See, e.g., NeTHERLANDS: COMPlete QUESTIONNAIRE INCluding Bilateral Follow-uP for the 2000 Rérort on Progress (OECD Econ. Dep't Working Paper No. 1B, 1999) [hereinafter NETHERLANDS]; UNITED STATES REPLY TO OECD SURVEY (OECD Econ. Dep't Working Paper, 1999) [hereinafter U.S. REPLY]. 
which do not provide good value for money. By reducing interest costs in the future, such measures can make other programs more affordable. The Clinton Administration took this approach, building up a budget surplus through a mix of progressive tax increases, selectively reduced spending, and good fortune. ${ }^{36}$ In this way, the United States was part of an international trend; most rich democracies were pursuing policies to reduce debt burdens and thus debt service. As the Economic Policy Committee of the European Community put it, it was important to realize "the contribution which budget discipline can make via a lower interest burden to meeting the costs of ageing populations, especially in high debt countries., ${ }^{37}$

In short, while future trade-offs are an important consideration, there is little reason to assume that health care for the elderly per se should be the loser. Policy-makers would do best if they presently adopted cautious budget policies on all dimensions.

\section{THE OTHER SidE OF THE EQUATION: THE ELDERLY AS WORKERS}

In other countries, health care for the elderly and for workers are not really separate subjects; in essence, all are grouped in the same insurance pools. Health care arrangements then neither push nor pull people in or out of the work force. Cash income is another story: In most wealthy democracies, the sources of pensions for the elderly are very different from wages for workers. Hence, the choice to work or retire depends in part on governmental policies that set the terms for both contributing to and receiving pensions. There are obvious financial benefits from policy changes that, at the very least, stop discouraging individuals from working longer. Moreover, policies that discourage working with confiscatory effective tax rates seem unfair. By one calculation, the implicit tax on Dutch workers who work past the age when they could take retirement is $141 \%$. In the United States, there is no such penalty. ${ }^{38}$ In the future, reduced morbidity among the elderly should mean greater ability to work

36. The end of the Cold War allowed a reduction in U.S. military spending totaling $1.5 \%$ of GDP. Legislation in 1990 and 1993, combined with a dose of good luck, raised revenues by $3.0 \%$ of GDP. In turn, debt service costs fell steadily. See CONG. BUDGET OFFICE, BUDGET AND ECONOMIC OUTLOOK: FISCAL YEARS 2002-2011 143, 147, 149 (2001). These policies would, if maintained, have paid for most of the projected increases in spending for Social Security and Medicare over the next 30 years. See WhITE, supra note 3.

37. European CMty. Econ. Pol'y Comm., Progress Report to the Ecofin Council on the Impact of Ageing Populations on Public Pensions Systems 41 (2000).

38. Gruber \& Wise, supra note 12 , at 47. 
at, for example, age sixty-seven. Changing job structures may mean that a larger share of jobs can be done by older persons, while the same emphasis on mental rather than physical abilities may require that individuals begin productive work at an older age. As a result of both more time spent in training while young and the greater ability to be productive while old, policies that encourage later retirement may be more equitable than current policies. On the other hand, the argument for raising ages of entitlement to pensions may be taken too far. Some work, such as driving delivery trucks or working in kitchens, is physically demanding, and therefore policies that alter pensions in order to encourage people to work longer should recognize that this makes more sense for some types of workers than for others. But this difference can be recognized in part by basing entitlement to pensions on years in the work force as much as age: Workers whose jobs involve physical labor are likely to have spent less time being educated, and so to have entered the work force sooner than those workers whose jobs allow them to maintain productivity later in life. On the whole, the most reasonable response to the fact that population aging under current law would produce a shrinking labor force is to adjust pension laws and other policies so as to encourage greater labor force participation. By raising revenues, this in turn would make health care costs for the elderly more affordable.

To summarize, there is little ethical or financial reason to focus on reducing health care spending on the elderly. Policies to increase workforce participation, so long as they are not punitive, are a much better idea. Both conclusions are supported by recent analyses from the OECD and European Community (EC). For example, the OECD's "seven principles to guide the reforms needed to address demographic pressures" only call for "a greater focus on cost-effectiveness in health care," rather than any direct reduction in the entitlement to care. ${ }^{39}$ Those principles include reducing incentives for early retirement, diversifying the mix of pension sources, and improving labor market opportunities for older workers. ${ }^{40}$ The first questions in the OECD's review of national policies to address the challenges of an aging society focus on "[r]etirement [i]ncentives and [1]abour [s] upply."

39. Org. For Econ. Cooperation \& Dev., Policy Report: Maintaining Prosperity in an AGEING SOCIETY 1, 2 (1998).

40. Id. at 2.

41. NETHERLANDS, supra note 35; U.S. REPLY, supra note 35; GERMANY: QUESTIONNAIRE 2000 ORIGINAL REPORT (OECD Econ. Dep't Working Paper, Jan. 27, 2000), available at http://www.oecd.org/dataoecd/22/55/2425505.pdf (last visited Dec. 23, 2003). 
has also highlighted the importance of labor supply issues. ${ }^{42}$ Policies to increase labor supply could include further encouragement of childbearing and of women entering the work force (though these may seem to be contradictory goals). A September 2003 review in the OECD Observer recommended a "radical policy package" that "would include the following steps: eliminate early retirement schemes; make old-age pension schemes actuarially neutral so that pensions fully reflect time spent in work; raise standard retirement ages; increase childcare subsidies; eliminate tax discrimination against female participation; and enhance the role of part-time work." ${ }^{, 43}$ Apparently denying health care specifically to the elderly was viewed as more than "radical," because it was not been suggested.

No one should imagine that policies to increase the workforce are easy to implement. Employers prefer not to hire older workers, other things being equal. ${ }^{44}$ Additionally, factors such as the rate of female participation in the labor force depend on more than pensions. ${ }^{45}$ Yet, it is instructive that the trend among analysts and policymakers in other wealthy democracies is to emphasize workforce and pension responses to the challenges of an aging society and to view health care as a different question-one that should be treated on its own merits for all citizens.

\section{MAtching Services to NeEd For an Aging Population}

While the impact of an aging population on the cost of health care is likely to be less significant than many have predicted, its implications for the organization of our health care system will surely be enormous. The elderly consume both more and different health care services than younger persons, and our health care system will need to adjust both its supply and its structure to provide these services.

\section{A. Appropriateness of Care for the Elderly}

Generally speaking, aged bodies do not work quite the same way as

42. See European CMTy. ECON. POL'Y COMm., supra note 37.

43. Jean Phillipe Cotis, Population Ageing: Facing the Challenge, OECD ObSERver, Sept. 26, 2003, available at

http://www.oecdobserver.org/news/fullstory.php/aid/39/Population_growth:_facing_the _challenge.html (last visited Dec. 23, 2003).

44. ORG. FOR ECON. COOPERATION \& DEv., WORK FORGE AGEING: CONSEQUENCES AND

POLICY RESPONSES (OECD Working Paper No. AWP4.1, 1998).

45. See European CMTy. ECON. POL'y COMM., supra note 37, at 41. 
those of young people. Not only are they particularly prone to such diseases as osteoporosis and Alzheimer's, ${ }^{46}$ but clinical indicators may have different implications for the old as compared to the young. For example, lower blood pressure appears to be a sign of good health in young people, but bad health in very old people. ${ }^{47}$ In addition, low cholesterol is associated with mortality in older persons, though that may not be evidence against prescribing statins. ${ }^{48}$ Metabolic processes in older people can also differ from those in younger persons; thus the elderly are both more prone to anorexia and more prone to hypotension after eating. ${ }^{49}$ There are also cases in which they appear to metabolize drugs differently than do the young. ${ }^{50}$ For all these reasons, studies done on other populations may not accurately predict the performance of treatments among the elderly.

The elderly may also interact with medical professionals differently. Age creates comprehension and communication problems; at the same time, relationships with physicians and their offices can take on a social role-the medical office as a place to go-which fits poorly with the cost control needs of medical payers. Moreover, the elderly are more likely to suffer from chronic illnesses and multiple conditions, which require more complex coordination of care than is the norm for younger patients. America's "medical care ad-hoc-racy" is not very good at such coordination. ${ }^{.1}$

\section{B. Supply of Caregivers for the Elderly}

Thus, there is good reason to believe that care for some of the elderly can require a different skill set, both for individuals and for institutions, than is needed to care for most other patients. ${ }^{52}$.The need for training and

46. John E. Morley, Editorial: Hot Topics in Geriatrics, 58 J.GERONTOLOGY, SERIES A, MEd. SCI. 30, 30-31 (2003).

47. Tamara B. Harris, Commentary: Aging Well and Aging Poorly: Primary and Secondary Low Blood Pressure, 58 J. Gerontology, Series A, Med. SCi. 662, 662 (2003).

48. Morley, supra note 46, at 30.

49. John E. Morley, Editorial: Drugs, Aging, and the Future, 57 J. Gerontology, Series A, MED. SCI. 2, 6 (2002).

50. Eric C. Petrie et al., Increased Plasma Norepinephrine Response to Yohimbine in Elderly Men, 58 J. Gerontology, Series A, Med. SCi. M155, M155 (2003).

51. David M. Lawrence, My Mother and the Medical Care Ad-Hoc-Racy, HEALTH Afr., Mar.Apr. 2003, at 238.

52. See Christine Tassone Kovner et al., Who Cares for Older Adults?, Health Aff., Sept.Oct. 2002, at 78 . 
research in geriatric medicine is already high and will grow dramatically. Yet the extent of such a focus varies significantly across countries and is particularly low in the United States. Greg O'Neill and Patricia P. Barry report that "only three of the nation's 145 medical schools have a full-time department of geriatrics that requires a mandatory rotation in geriatrics for students and residents, and less than $3 \%$ of all medical students take even one course in geriatrics. In contrast, every medical school in Great Britain and 19 of Japan's 88 medical schools have such a department. ${ }^{.53}$ Only twenty-three percent of American nursing programs have a required course in geriatrics. ${ }^{54}$ Yet, while the need for training in geriatic care has been obvious for years, there has been hardly any response within American academic medicine. The government could try to encourage changes in medical and nursing school curricula, but governments generally have great difficulty shaping behavior within medical institutions or medical supply more generally. In any event, there is a very long way to go, and it is highly unlikely that training will catch up to need before many decades have passed. ${ }^{55}$

While the medical needs of the elderly pose significant workforce challenges, these are exacerbated by the need for an expanded supply of the broad set of quasi-medical and non-medical services grouped under the title "long-term care." As Joshua Wiener explains, "[L]ong-term care services are largely provided by unskilled paraprofessionals, who are overwhelmingly women and disproportionately represented by racial minorities and ethnic groups. Low wages and benefits, hard working conditions, heavy workloads and a job that has been stigmatized by society make worker recruitment and retention difficult." ${ }^{56}$ Helping people to dress, eat, urinate, and defecate simply is not an attractive career. Dealing with individuals in various stages of dementia is trying. Perhaps these jobs could be made more attractive with large dollops of money, but difficulties like lack of respect, dead-end jobs, the cultural gap, and the physical and mental stress of the work are not easily addressed with money. ${ }^{57}$ People who do this kind of work with compassion often have some inner calling or

53. Greg O'Neill \& Patricia P. Barry, Training Physicians in Geriatric Care: Responding to Critical Need, PUb. POL'Y \& AGING ReP., Winter 2003, at 17, 17.

54. Mathy Mezey \& Christine Tassone Kovner, Nursing's Geriatric Workforce Caring for Older Adults, PUB. POL'Y \& AGING REP., Winter 2003, at 22.

55. See O'Neill and Barry, supra note 53.

56. Joshua M. Wiener, Country Portrait: United States of America, in Four COUNTRY Conference, Aging and Health Policy 87 (2001).

57. See Susan C. Eaton, Frontline Caregivers in Nursing Facilities: Can Policy Help in Recruitment and Retention Crisis?, PUB. POL'Y \& AGING REP., Winter 2003, at 8. 
strength, which is hard to produce with any kind of policy. And, even that inner light may burn out quickly for many careproviders: Scandals in nursing homes surely reflect the greed of some for-profit proprietors, but may also show the difficulty of finding workers and supporting them in a culture of caring for the elderly.

As society ages, we should expect those challenges to worsen, for there will be greater need, and fewer workers to meet the need. Increasing the number of workers by encouraging people in their late sixties to work is unlikely to be the answer to filling the physically demanding jobs of caring for the elderly-lifting and clothing individuals in their eighties, for example. If future workers on average will be better-educated, that may make it easier for them to work longer at white-collar jobs, but is unlikely to make them more willing to work in jobs providing personal services to individuals who need help with daily living. Moreover, some of the same trends that increase women's labor force participation (and so increase the total workforce), such as the breakdown of barriers to more and more types of jobs, may further reduce interest in joining the nursing and other caring workforces.

In the end, then, where will the caregivers be found? Some nations are coming to rely more on immigrant nurses, and this policy may be worth considering and encouraging. However, this may not be so easy to arrange. If giving care is not likely to be an attractive career; perhaps it can be made preliminary to, or a condition for embarking, on a career. Systems of national service, or of student aid conditional upon prior service, might provide some of the necessary labor. ${ }^{58}$ Yet that too poses challenges, ranging from how to create those programs to how to ensure that the work is done well.

\section{Who Should Pay for Long-Term Care?}

Long-term care is a mix of professional services, nonprofessional caregiving, and the expenses of daily life. A nursing home provides shelter and food that, conceptually, are not medical benefits at all. Nor are they really "risks" in the same sense as medical expenses: Many people will not get very sick in a given year, while everyone must live and eat somewhere. The fact that many services are not professional helps explain why they have historically been separate from medical benefits-excluded from the insurance programs and left for the state, provinicial, or local governments

58. I say conditional upon prior service because I do not trust any system's ability to enforce requirements for service after individuals have already received their benefit. 
to provide. ${ }^{59}$ Canada has no long-term care guarantee comparable to its Medicare, ${ }^{60}$ and indeed "no national standard" for such care. ${ }^{61}$ Germany and Japan have only instituted such programs very recently. ${ }^{62}$ The Netherlands is exceptional in having had fairly universal-though not satisfactory to all-arrangements for quite a while. ${ }^{63}$ In spite of this history and related budget concerns, the policy trend is modest movement toward expansion of long-term care benefits. Japan and Germany's creation of long-term care programs in the 1990s is especially remarkable in light of Japan's economic stagnation and the high costs of German reunification. It seems likely that one reason for these expansions is that long-term care services, being associated with evident disability, cannot be accused of creating disincentives to work. In Japan's case especially, long-term care benefits might even make it easier for women to participate in the workforce, as daughters or daughters-in-law are freed from having to stay home with aged parents. So, unlike pensions, the international concern about improving labor-market participation does not militate against expansion of long-term care benefits.

One could still raise questions regarding who should be responsible for long-term care. Should people save for themselves or through social insurance, and should programs be pay-as-you-go or pre-funded? In practice, as opposed to academic speculation, private-market solutions to the need for long-term care do not seem to be a major policy trend. ${ }^{64}$ Prefunding of long-term care is less practical than the pre-funding of pensions, and could be crowded out by saving for pensions. Pre-funding requires that costs be predictable, but long-term care benefits are much less predictable than pension needs because future patterns of disability are uncertain. ${ }^{65}$ If policymakers seek to create publicly-managed funds of

59. Mark Merlis, Caring for the Frail Elderly: An International Review, HEALTH AFF., MayJune 2000, at 142.

60. Raisa Deber, Country Portrait: Canada, in Four Country CONFERENCE, supra note 56, at 57.

61. Merlis, supra note 59, at 142.

62. John C. Campell \& Naoki Ikegami, Long-Term Care Insurance Comes to Japan, HEALTH AFF., May-June 2000, at 26; Alison E. Cuellar \& Joshua Wiener, Can Social Insurance for LongTerm Care Work?: The Experience of Germany, HEALTH AFF., May-June 2000, at 8.

63. Paul Schnabel, Country Portrait: The Netherlands, in Four Country CONFEREnCE, supra note 56 , at 79 .

64. The standard private-market approach would be voluntary long-term care insurance. The difficulty is it would be almost impossible to get people to voluntarily buy this insurance at the prices at which it would be offered.

65. Stephane Jacobzone et al., long Term Care Services to Older People, A 
private assets to help pay for future pension costs (as has been proposed in the United States and other countries), there will be fears of the government managing too large a pension fund. ${ }^{66}$ Given those fears of letting governments manage too much money, they are not likely to be allowed to set up further investment funds for long-term care.

Long-term care also poses, in a particularly acute form, an issue that is common to all social insurance: Who is really being protected by the programs? Pensions, for example, protect not only the elderly, but their children, who might otherwise have to pay to support parents. Medicare's popularity also must be related to the fact that, if workers' parents and grandparents were not guaranteed medical insurance, the workers would be more likely to get stuck with huge and unpredictable medical bills. Yet, long-term care would protect children not only from a financial but also a physical burden-the chance that middle-aged or even older women, in particular, might have to assist aged parents with activities of daily living. Germany offers a cash benefit, in lieu of a service benefit, in part on the assumption that many children would choose to care for their parents, but would want to replace some of the income that they otherwise would earn in the market. Family caregivers are even given time off and pension credits. ${ }^{67}$ Long-term care choices therefore involve uniquely complex relationships among the family, the market, and the state.

Demand for long-term care of various sorts will increase. Yet, as noted above, long-term care's finance and delivery tend to be separated from core health programs. In the Netherlands it is part of the "exceptional medical expenses" system, wholly public and separate from the health insurance funds. In the United States, most long-term care is not part of the universal entitlement of Medicare, but instead public support is confined to Medicaid, a means-tested entitlement, and some programs for veterans. This would not appear problematic if the set of caregivers and institutions were entirely separate from the mainline health system. Yet they are not, and separate financing pools can cause managers to concentrate on cost-shifting (hospitals to nursing homes and back; states to federal government and back) more than care-giving.

On balance, the complexities of long-term care in particular do not challenge the above conclusion-that health care costs for the elderly per se should not be viewed as an economic burden that must be fixed. First,

Perspective on Future Needs (OECD Working Paper No. AWP 4.2 Eng., 1998).

66. WHITE, supra note 3 , at 161-67.

67. Cuellar \& Wiener, supra note 62 , at 17. 
coverage in many countries is partial at best. ${ }^{68}$ Second, some coverage might even have helpful labor market effects. Third, any projections of future costs involve great uncertainties due to unpredictable morbidity. As with health care more generally, the trend in other countries is more toward guaranteeing coverage than toward taking it away.

\section{CONCLUSION}

This Article has reviewed the health policy implications of an aging society. As stated at the outset, claims that a growing proportion of elderly persons in the population require reductions in social guarantees of access to health care are a common part of analytic and policy discourse. Yet, I have argued, this discussion tends to overstate some challenges and understate others.

For a number of reasons, I have contended that the challenge of health care costs posed by population aging is exaggerated. First, the contribution of population aging to total medical costs is small compared to other trends. Second, in America, separate budgeting of Medicare costs makes increases in spending on the elderly seem more significant than they should from a broader societal perspective. Third, claims that higher government spending on health care is inherently harmful to the economy deserve great skepticism - there may be mild negative effects but, so long as governments actually pay for the costs, there should be little long-term harm. Fourth, the claim that a growing proportion of the "old old" especially threatens higher costs is not supported by existing data. What might be termed bioethical concerns caused by aging populations can also be overstated. Arguments posing a conflict between "the young" and "the old" are suspect because normal young people generally wish to become old eventually, so benefits for the elderly are also benefits for themselves. Notions that the old should receive less medical care so as to leave more resources for the young do not fit well with ethical or religious traditions that value human life per se. Moreover, the border between "young" and "old" is not so easily defined: If by "old" we mean people over age sixty-five, then many of those individuals can be very productive members of society. If the concern is actually that people who are so old as to be mostly dependent should give way to the young, then that concern must not only overcome the basic ethical objection to valuing some lives more than others, but the fact that the "old old" do not represent a major factor in increasing health care costs.

68. Merlis, supra note 59, at 141-44. 
It is true that in any situation where the share of the population that is working declines and the share that is retired increases, there is a resourcedistribution conundrum. Retirees always live on the production of current workers; social arrangements differ only in how they claim that production-through investment income, intra-family transfers, or communal sharing (government or other) arrangements. Thus, an increasing proportion of retirees means either that retirees get less (if their share of workers' production is stable) or workers keep less (if workers' contribution to retirees increases with the larger proportion of retirees). This distributional concern applies not only to consumption of health care but, more directly, to pension finance. As this Article has argued, however, reduction of health care for the elderly seems one of the least desirable responses to this challenge. Skepticism about reducing health care for the elderly appears to have become the norm, as referenced above, in analyses by the Organization for Economic Cooperation and by the European Community. Those analyses and this Article argue that the most appropriate response is to increase the supply of workers, particularly by having policies to encourage later retirement.

In short, an aging society poses an array of challenges, but health finance is neither a major factor nor the proper lens through which to perceive the most important financial and ethical dilemmas. In fact, the health policy problem that appears to be most directly related to aging is the anticipated health care and caregiving labor shortage. The general concern about how economies will function with the low proportion of workers that are currently projected is especially relevant to how the health sector, which employs large numbers of low-skilled workers in relatively undesirable jobs, will function when there is an even greater need for those workers.

It is not clear that any government will be able to do much to address these labor supply problems. However, a range of policies-from encouraging immigration to providing training to subsidizing such work as national service-may be relevant and appropriate. Policymakers would do well to spend more time thinking about labor issues-and less about how to define insurance benefits or pay for health care thirty years from now. 